\title{
Identification of Follower Status Based on Male Proximity Score in Crested Macaque
}

\author{
Andre Pasetha $^{1 *}$, Lisa Michelle Danish4 ${ }^{4}$ Dyah Perwitasari-Farajallah ${ }^{1,3}$, Muhammad Agil $^{2}$, Antje Engelhardt ${ }^{4,5,6}$ \\ ${ }^{1}$ Department of Biology, Faculty of Mathematics and Natural Sciences, IPB University, Bogor, Indonesia \\ ${ }^{2}$ Department of Veterinary Clinic, Reproduction, and Pathology, Faculty of Veterinary Medicine, IPB University, Bogor, Indonesia \\ ${ }^{3}$ Primate Research Centre, IPB University, Bogor, Indonesia \\ ${ }^{4}$ Junior Research Group of Primate Sexual Selection, German Primate Center, Göttingen, Germany \\ ${ }^{5}$ Courant Research Center Evolution of Social Behavior, Georg August University, Göttingen, Germany \\ ${ }^{6}$ School of Natural Sciences and Psychology, Liverpool John Moores University, Liverpool, UK
}

\section{ARTICLE INFO}

\section{Article history:}

Received January 5, 2018

Received in revised form February 10, 2020

Accepted February 20, 2020

KEYWORDS:

consortship,

following,

alternative strategy,

male proximity score,

Macaca nigra

\begin{abstract}
Crested macaque live in multimale-multifemale social groups where temporary association (consortship) typically occurs. Current theory and these limited qualitative observations suggest the hypothesis that behavior functions as a means for males to gain access to fertile females. The aim of this study was to investigate follower status based on quantitative method. Males were classified as either "consort males," "followers," and "non-followers" based on proximity maintanance every 15 minute uses scan sampling. Tactics used by followers were classified into 1) individual challenge, 2) coalitionary challenge, 3) abandoned takeover, and 4) opportunistic takeover. The proportion of successful takeovers by followers was calculated by dividing the number of takeovers by followers by the total number of observed takeovers. The proportion of followers is higher than average on D-5 and earlier, D-4, and D-3. Only two of the four consort takeover tactics were used by followers. For abandoned which made up $40 \%$ and for individual tactic was made up to $\mathbf{1 1 . 5 \%}$ of consort takeovers tactic used. This study contribute to our understanding of alternative mating strategy in primate and provide the first quantitative data demonstrating that following is an alternative mating strategy in crested macaque (Macaca nigra).
\end{abstract}

\section{Introduction}

Crested macaque live in multimale-multifemale social groups characterized by matrilineal dominance hierarchy with stable female philopatry and male emigration (Duboscq et al. 2017). In this system females usually mate with more than one partner and temporary association (consortship) between male and female typically occurs, lasting from minutes to several days (Altmann 1962; Hall and DeVore 1965; Bulger 1993; Engelhardt et al. 2004; Engelhardt et al. 2006; Higham et al. 2009; Dubuc et al. 2012; Girrard-Buttoz et al. 2014). Consortship is a predominant mating strategy in male primates in multi-male, multi-female groups in which consorting males prevent competitors from gain access to fertile females (Andersson 1994; de Ruiter et al. 1994). This

\footnotetext{
* Corresponding Author

E-mail Address: apasetha@gmail.com
}

behaviour has been shown to significantly increase reproductive success and reproductive skew of males (Engelhardt et al. 2006; Pipe 2011). The duration of consortships and the number of partners which a single female may consort varies tremendously between species (Tutin 1979; van Noordwijk 1985; Manson 1992). Much of crested macaques mating during the period of likely ovulation occurs within consortships.

The link between male reproductive success and reproductive skew in primates designated as the Priority of Access (PoA) model. This model predicts male reproductive success should correlate with male dominance rank and controls for female cycle synchrony (Altmann 1962). Reproductive success and skew will be also be affected by alternative mating strategies (Danish and Palombit 2014). Previous research reveal the limits of PoA model, highlighting the potential of alternative mating strategies in a number of primates (Alberts et al. 2003; Wroblewski 
et al. 2009; Bissonnette et al. 2011; Dubuc et al. 2011; Danish and Palombit 2014). The alternative strategies are a means for subordinate males to queue jump, sire offspring, and reduce the ability of high ranking males to monopolize the fertile females (Abbott et al. 2003; Alberts et al. 2003; Danish and Palombit 2014). Studies of alternative strategies in primates are relatively rare, with most studies examining: sexual bimaturism in mandrills (Mandrillus sphinx) (Setchell and Dixson 2001; Setchell 2003) orangutans (Pongo pygmaeus) (Maggioncalda et al. 2000; Atmoko et al. 2002; Atmoko and van Hooff 2004) and sneak copulations and coalition formation in a number of primates living in multimale-multifemale system (Noë and Sluijter 1995; Soltis et al. 1997; Soltis et al. 2001; Alberts et al. 2003; van Schaik et al. 2004).

Recent studies indicate that "following" is an alternative mating strategies in which males maintain proximity to the consort pair for extended times. Following has been observed in olive baboons (Papio hamadryas anubis, Hall and DeVore 1965; Strum 1982, 1987, 1994; Bercovitch 1988; Sapolsky 1990; Forster and Strum 1994; Danish and Palombit 2014), yellow baboons (Papio hamadryas cynocephalus, Hausfater 1975), Barbary macaques (Macaca sylvanus, Kuester and Paul 1989), long-tailed macaques (M. fascicularis, Engelhardt et al. 2006) and rhesus macaques ( $M$. mulatta, Kaufmann 1965). Danish and Palombit (2014) proposed "following" as an alternative mating strategy in olive baboon (Papio hamadryas anubis) based on quantitative method. This paper is first present for identify status of following and tactic used by followers in crested macaque (Macaca nigra). While following has been shown to be an alternative mating strategy in olive baboons (Danish and Palombit 2014), it has not been quantitatively examined in macaques. Here I present the first quantitative approach from wild crested macaques (Macaca nigra) living under natural condition in Tangkoko Nature Reserve. We first asked: 1) When does following occur more frequently? Following is likely to benefit males most during the period of likely ovulation (D-4 until D-1 before deflation of the sexual swelling) (Gesquiere et al. 2007; Higham et al. 2008). We predicted the number of followers will increase during conception period; 2) Is following an alternative mating strategy in crested macaque? Based on description of following in the literature, We predicted that males would gained access to fertile female via following since the current theory suggest that following functions as a means to gaining access to fertile female (Danish and Palombit 2014); 3) What tactics do followers use to gain access to the fertile female? We classified the tactics used by followers based on Danish and Palombit (2014). We predicted non-followers would use individual challenge as a consort takeover tactic more than followers, and the abandoned consort takeover would be used by followers more than non follower since the first male able to reach the abandoned female, after the consort male abandons the female gains access to her (Danish and Palombit 2014).

\section{Materials and Methods}

\subsection{Animals and Study Site}

One habituated and identifiable group (R1) of crested macaques (Macaca nigra) was used in this study. We observed the group from May 2015 to July 2016 in the Tangkoko Nature Reserve, North Sulawesi, Indonesia ( $1^{\circ} 34^{\prime} \mathrm{N}, 125^{\circ} 14^{\prime} \mathrm{E}$; an elevation of $1,350 \mathrm{~m}$ ). The reserve was established in 1980 and comprises an area 8.867 ha (Rosenbaum et al. 1998). The location consists of secondary rainforest and primary rainforest and full complement of floral and animal communities as a typical in Wallacea region. The annual rainfall between October and May, with ranges between 1,550 and 2,400 $\mathrm{mm}$. Monthly mean minimum air temperature was constant ca. $24^{\circ} \mathrm{C}$ throughout the year and the mean maximum air temperature was $27.5^{\circ} \mathrm{C}$. During the study, the group consisted of 11 adult males, 33 adult females, 5 subadults, 29 juveniles, and 10 infants, in total 88 individuals. This group has been studied by other scientist since 2006. All members of the group were identified by different marks like a body features, missing fingers, scars, face etc. The study focused on adult males and swelling female during consortship period. Each observed consortship was observed from dawn to dusk at 05.00-17.30 every day for the duration of the period the females consorted; we observed 193 consortships ( $\mathrm{N}=11$ males; $\mathrm{N}=10$ females; $\mathrm{N}=608.93$ hours consortship duration).

\subsection{Reproductive State of Females and Period of Likely Ovulation}

All females that were not pregnant or lactating were considered cycling females. Cycling female crested macaques develope sexual swellings, which change in size throughout their cycle. Sexual swelling 
cues were used as an indication they would begin consorting soon. The swelling sizes were collected on each observation day, as well as the identity of all their observed consort partners and followers were recorded using ad libitum with Wintab 10 Odys. We define inflating as beginning of the swelling which the perinneal skin of female start to swollen. Swelling is a condition when the skin have fully swollen and the colour is red. Deflating was recognized with appearance of wrinkles in the perinneal skin or we can said no swelling. Ovulation occurs around time when the swelling undergoes rapid detumescence (Higham et al. 2008). The fertile period can be determined using the day of detumescence (D-Day), with preceding days denoted as D-1, D-2, D-3,..., D-n. The four days of preceeding deflation (D-4, D-3, D-2, and D-1) are the most likely of conception period (Higham et al. 2012).

\subsection{Follower Status}

Males were classified as either "consort male", "follower", or "non-follower" during consortship period. Consort males were identified based on extended proximity maintenance during data collection. We considered a male consort is male that remained in close proximity to a cycling female, following her as she traveled, and mate guarded her from the other males for at least ten minutes. For remaining males in the group, we identified male status using a male proximity score (MP-score) (Danish and Palombit 2014), which was calculated for each male separately. or each observation day, wecollected male-male distance data via animal scan sampling (Altmann 1974) at 15 minute interval throughout the observation day.

Distance was recorded as $1 \mathrm{~m}, 2 \mathrm{~m}, 3 \mathrm{~m}, 4 \mathrm{~m}, 5$ m, $10 \mathrm{~m}, 15 \mathrm{~m}, 20 \mathrm{~m}, 25 \mathrm{~m}$ between consort male and each visible male. If a consort takeover occurred, we calculated the MP scores separately for each consortship period. If a consorship continued the next day, we calculated the MP score only using data from the current day. The MP score is calculated as below for each consort male-male dyad, for each scan sample intervals:

$$
\begin{aligned}
\mathrm{MP}= & \sum(1 / \text { distance } 1) *([1 / \text { number intervals }] * 100)+ \\
& \ldots(1 / \text { distancen }) *([1 / \text { number intervals }] * 100)
\end{aligned}
$$

The MP score components were calculated from each scan interval by taking the product of the reciprocal of the distance between males and the percentage of time at that distance. The score is the sum of all such components, from the first scan sample to the nth scan sample. If a male was not visible during a particular scan sample, the component value for that sample was zero. Based on preliminary data, males with a score of $\geq 5.5$ should be classified as followers, while males with a score less than 5.5 were classified as non-followers.

\subsection{Classification of Consort Takeover Tactic}

Consort takeover tactics were used by followers has been classified: 1) individual challenge, 2) coalitionary challenge, 3 ) abandoned takeover, and 4) opportunistic takeover (Danish and Palombit 2014). Individual challenge means a single male directed aggression at the consort male; Coalitionary challenge is the direction of aggression toward the consort male by male-male coalition; Abandoned takeover is defined when the consort male moved away without any aggression; Opportunistic takeovers is the new male gained access to the fertile female as the result of some form of external distraction.

\subsection{Proportion of Successful Takeover by Followers}

Female cycle day was determined using the day of detumescence (D-Day), with preceding days denoted as D-1, D-2, D-3, ...., D-10 (Gesquiere et al. 2007). The proportion of sucessful takeovers by followers was calculated by dividing the number of takeovers by followers by the total number of observed takeovers. The proportion of successful takeover before D-4 were combined because these days are not likely days of conception and females vary in the number of these days during which they consort (Bercovitch 1995; Gesquiere et al. 2007).

\section{Results}

\subsection{Follower Status}

The proportion of followers is higher than average on D-5 and earlier, D-4, and D-3 (Figure 1). Surprisingly, the proportion of followers is lower than average on D- 1 and average on $\mathrm{D}-2$. The highest proportion of following occurs at D-4 $(0,1096)$ and the lowest proportion of followin at D-1 $(0,0356)$. Contrary to our prediction, following occurs more only during part of the period of likely ovulation, and (contrary to our predictions) prior to that period. 
3.2. Consort Takeover Tactic Used by Follower Only two of the four consort takeover tactics were used by followers (Figure 2). For abandoned, which made up $40 \%$ of consort takeovers tactic used by followers. While abandoned consort takeovers were primarily carried out by nonfollowers, supported our prediction. Only $11.5 \%$ of males using the individual tactic were followers. This indicate that followers mainly used abandoned consort takeovers as a mainly a means to gain access to fertile females.

\subsection{Proportion Successful of ConsortTakeover} Overall, $25.4 \%$ of consort takeovers were executed by males who were followers of the targeted consortships. Notably, the percentage of consort takeovers by followers increased up during the periods of likely ovulation, reaching a maximum at D-3, but declining after (Figure 2).

\section{Discussion}

Followers were most involved in several days likely conception period, between D-4 until D-2 (Figure 1). We propose that such following activity allows followers to gain access to swelling female. Following provides males with access to fertile females; our data therefore support the conclusion that following is an effective alternative mating strategy. Two consort takeover tactics were used by followers (Table 1 ). For

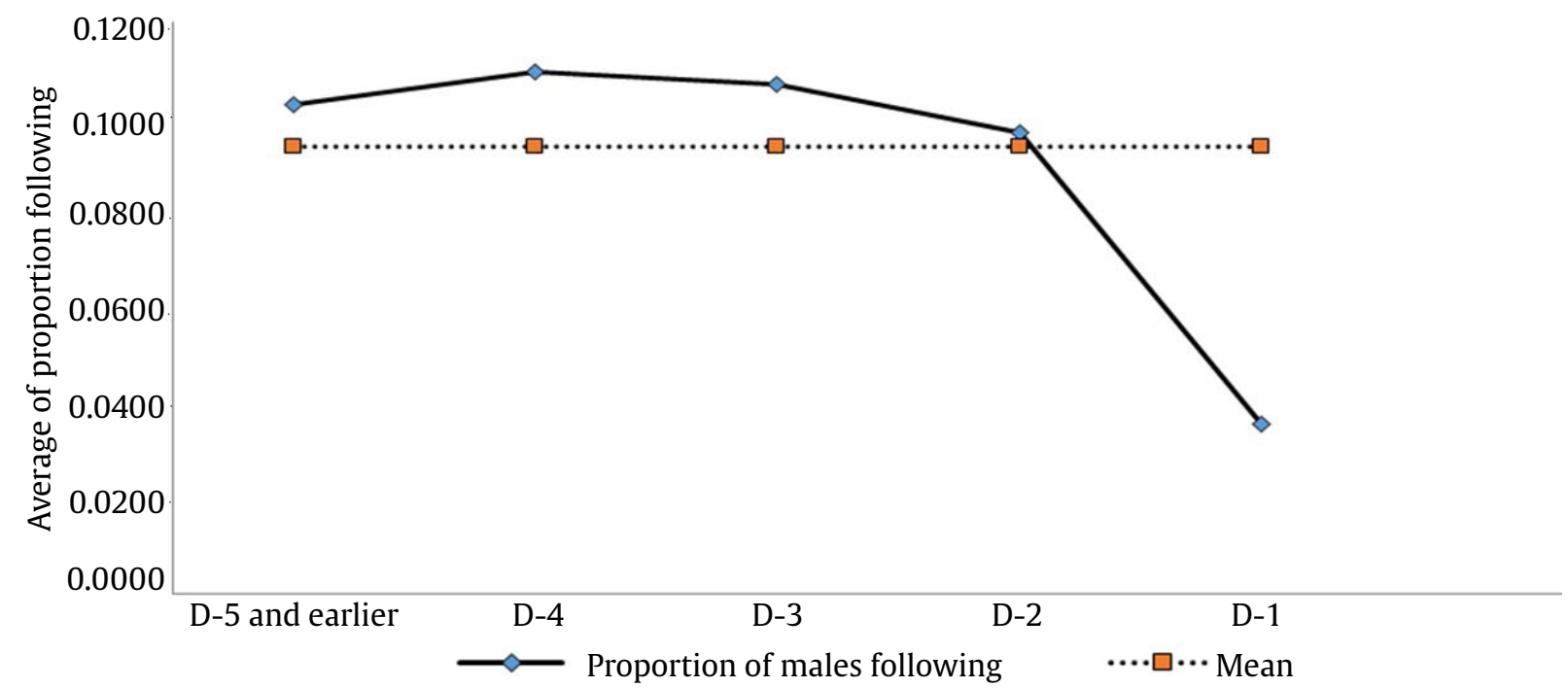

Figure 1. Cycle Day related to proportion of males following in cretsed macaque (Macaca nigra)

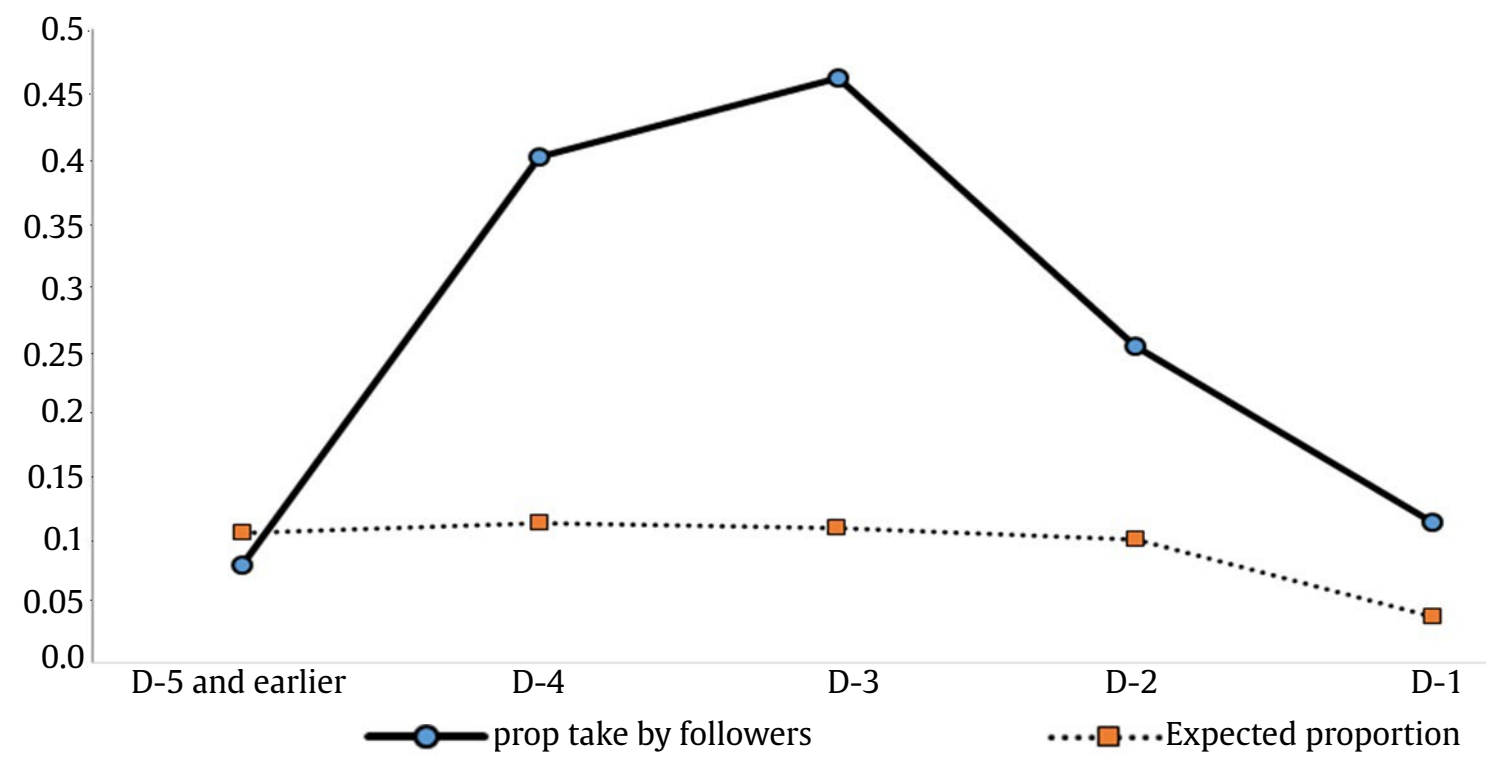

Figure 2. Proportion successful consort takeover by follower 
abandoned, which the most of consort takeovers tactic used by followers. Abandoned consort takeovers were primarily carried out by followers, which partially supported my prediction. This indicate that followers used abandoned as a mainly consort takeovers tactic. Surprisingly, both of these consort takeover tactics were used more by non followers than followers (Table 1), suggesting following is not component of a non-followers strategies.

Contrary with our predictions, abandoned consort takeovers was used equally by non followers; I suggest that this pattern is due to the nature of such consort takeovers, which are categorized by seizing a chance to obtain access to a female. Since consort males typically remained in close proximity to the consort female (Pasetha pers. obs.), there appeared to be little opportunity for sneak copulations, supported by other studies of baboons (Alberts et al. 2003; Danish and Palombit 2014).

Based on our findings, we propose that following is an alternative mating strategy in crested macaques. While males of all dominance rank gain access to fertile female by following, my data indicate that following provides mid- and low-ranking males, who would otherwise be excluded from mating, with access to females. We suggest that strategy use by low- and mid-ranking males has impacted the strategies of high-ranking males, resulting in their adoption of the following strategy. We propose that the occurrence of following accounts for the well documented deviation from the priority of access model (Berard et al. 1993; Alberts et al. 2003; Wroblewski et al. 2009; Bissonnette et al. 2011; Dubuc et al. 2011, Danish and Palombit 2014) in other species, such as baboons. This study provide the first quantitative data demonstrating that following is an alternative mating strategy in crested macaques (Macaca nigra). Our finding that followers, rather than nonfollowers, typically pursue abandoned consort takeovers forces us to reexamine in male crested macaques.

Table 1. Percent consort takeovers tactic used by followers in crested macaque

\begin{tabular}{lccc}
\hline Tactic & Follower & Non follower & Percent followers \\
\hline Abandoned & 6 & 15 & 40.0 \\
Individual & 3 & 26 & 11.5 \\
Total & 9 & 41 & 22.0 \\
\hline
\end{tabular}

\section{Acknowledgements}

We thank all the team members of the Macaca Nigra Project at Tangkoko for their guidance, knowledge, encouragement, suggestion, good advice during our research. My especially heartiest gratitude and heartleft appreciation to Lisa Michelle Danish who has given me chance to join in her project during 2 years and also for her financial support. We gratefully acknowledge the permission of the Department for the Conservation of Natural Resources (BKSDA) in Manado, for all permits provided for conducting research in Tangkoko Nature Reserve.

\section{References}

Abbott DH et al. 2003. Are subordinates always stressed? A comparative analysis of rank differences in cortisol levels among primates. Hormones and Behavior 43:6782. DOI:10.1016/s0018-506x(02)00037-5

Alberts SC et al. 2003. Queuing and queue-jumping:longterm patterns of reproductive skew in male savannah baboons, Papio cynocephalus. Anim Behav 65:821-840. DOI:10.1006/anbe.2003.2106

Altman SA. 1962. A field study of the sociobiology of rhesus monkeys, Macaca mulatta. Ann NY Acad Sci 102:338435. DOI:10.1111/j.1749-6632.1962.tb13650.x

Andersson M. 1994. Sexual Selection. New Jersey:Princenton University Press.

Atmoko SU et al. 2002. Male bimaturism and reproductive sucess in sumatran orang-utans. Behavioral Ecology 13:643-652.

Atmoko SU, van hoof JARAM. 2004. Alternative male reproductive strategies: Male bimaturism. In: PM Kappeler, and CP Van Schaik (Eds.). Sexual Selection in Primates: New and Comparative Perspective. Cambridge:Cambridge University Press. pp. 196-207.

Berard JD et al. 1993. Male rank, reproductive behavior, and reproductive success in free-ranging rhesus macaques. Primates 34:481-489.

Bercovitch FB. 1986. Male rank and reproductive activity in savanna baboons. International Journal of Primatology 7:533-550. DOI:10.1007/BF02736660

Bercovitch FB. 1988. Coalitions, cooperation and reproductive tactics among adult male baboons. Animal Behavior 36:1198-1209.

Bercovitch FB. 1995. Female cooperation, consortship maintenance, and male mating success in savanna baboons. Anim Behav 50:137-149.

Bissonnette A et al. 2011. Mating skew in barbary macaque males: the role of female mating synchrony, female behavior, and male-male coalitions. Behavioral Ecology and Sociobiology 65:167-182. DOI:10.1007/s00265010-1023-Z

Bulger JB. 1993. Dominance rank and access to estrous females in savannah baboons. Behaviour 1:67-103. DOI:10.1163/156853993X00434 
Danish LM, Palombit RA. 2014. "Following”, an alternative mating strategy used by male olive baboon (Papio hamadryas anubis):quantitative behavioral and functional description. Int J Primatol 35:394-410. DOI: 10.1007/s10764-013-9743-3

de Ruiter JR et al. 1994. Social and genetic aspects of paternity in wild long-tailed macaques (Macaca fascicularis). Behaviour 129:203-224. DOI: $10.1163 / 156853994$ X00613

Dubuc C et al. 2011. Testing the priority-of-access model in a seasonally breeding primate species. Behav Ecol Socibiol 65:1615-1627.DOI:10.1007/s00265-011-1172-8

Dubuc C et al. 2012. Do males time their mate-guarding effort with the fertile phase in order to secure fertilisation in Cayo Santiago rhesus macaques?. Hormone and Behavior 61:696-705.

Duboscq J et al. 2017. Degress of freedom in social bonds of crested macaque females. Animal Behaviour 123:4111426. DOI:10.1016/j.anbehav.2016.11.010

Engelhardt A et al. 2004. Assessment of female reproductive status by male longtailed macaques, Macaca fascicularis, under natural condition. Animal Behaviour 67:915-924. DOI:10.1016/j.anbehav.2003.09.006

Engelhardt A et al. 2006. Determinants of male reproductive success in wild long-tailed macaques (Macaca fascicularis): male monopolization, female mate choice or post copulatory mechanisms?. Behav Ecol Sociobiol 59:740-752. DOI:10.1007/s00265-005-0104-X

Forster D, Strum SC. 1994. Sleeping near the enemy:patterns of sexual competition in baboons. In: JJ Roeder, B Thierry, JR Anderson, and N Herrenschmidt (Eds.). Strasbourg:Universitie Louis Pasteur. pp. 19-24.

Gesquiere Let al. 2007. Mechanisms of sexual selection:sexual swellings and estrogen concentrations as fertility indicators and cues for male consort decisions in wild baboons. Hormones and behavior 51:114-25. DOI:10.1016/j.yhbeh.2006.08.010

Girard-Buttoz C et al. 2014. Mate-guarding constrains feeding activity but not energetic status of wild long-tailed macaques (Macaca fascicularis). Behav Ecol Sociobiol 68:583-595. DOI:10.1007/s00265-013-1673-8

Hall KRL, DeVore I. 1965. Baboon Social Behavior. In:I DeVore (Eds.). New York: Holt, Rinehart \& Winston. pp. 53-110.

Hausfater G. 1975. Dominance and Reproduction in Baboons (Papio cynocephalus): A Quantitative Analysis. Basel:Karger.

Higham JP et al. 2008. Baboon sexual swellings: information content size and color. Hormones and Behavior 53:452462. DOI:10.1016/j.yhbeh.2007.11.019

Higham JP et al. 2009. Female reproductive signaling, and male mating behavior, in the olive baboon. Hormone and Behavior 55:60-67.

Higham JP et al. 2012. Sexual signaling in female crested macaques and the evolution of primate fertility signals. BMCEvol Biol 12:89-110. DOI:10.1186/1471-2148-12-89

Kaufmann JH. 1965. A three-year study of mating behavior in a free-ranging band of rhesus monkeys. Ecology 46:500-512. DOI: $10.2307 / 1934881$

Kuester J, Paul A. 1989. Reproductive strategies of subadults Barbary macaque males at Affenberg Salem. In: AE Rasa, C Vogel, E Voland(Eds.). The Sociobiology of Sexual and Reproductive strategies. London:Chapman and Hall. pp. 93-109.

Maggioncalda AN et al. 2000. Growth hormone and thyroid stimulating hormone concentrations in captive male orangutans: implications for understanding development arrest. American Journal of Primatology 50:67-76. DOI:10.1002/(SICI)10982345(200001)50:1<67::AID-AJP6>3.0.CO;2-V
Manson JH. 1992. Measuring female mate choice in Cayo Santiago rheus macaques. Anim Behav 44:405-416. DOI:10.1016/0003-3472(92)90051-A

Noë R, Sluitjer AA. 1990. Reproductive tactics of male savannah baboons. Behavior 113:117-170. DOI:10.1163/156853990X00455

Noë R, Sluitjer AA. 1995. Which adult male savanna baboons form coalitions?. International Journal of Primatology 16:77-105. DOI:10.1007/BF02700154.

Pipe MN. 2011. Male-male competition, synchronous estrus, and reproductive skew in multimale-multifemale primate groups. Nebraska Anthropologist 26:5-18.

Rosenbaum B et al. 1998. Population densities of sulawesi crested black macaques (Macaca nigra) on Bacan and Sulawesi, Indonesia: effects of habitat disturbance and hunting. American Journal of Primatology 44:89-106. DOI:10.1002/(SICI)1098-2345(1998)44:2<89::AIDAJP1>3.0.CO;2-S

Sapolsky RM. 1990. Stress in the wild. Scientific American 262:116-123.

Setchell JM, Dixson AF. 2001. Changes in the secondary sexual adornments of male mandrills (Mandrillus sphinx) are associated with gain and loss of alpha status. Hormones and Behavior 39:177-184.DOI:10.1006/hbeh.2000.1628

Setchell JM. 2003. The evolution of alternative reproductive morphs in male primates. In: CB Jones (Eds.). Sexual Selection and Reproductive Competition in Primates: New Perspectives and Directions. Oklahoma:American Society of Primatologist. pp. 412-435.

Soltis J et al. 1997. Sexual selection in Japanese macaques II: female mate choice and male-male competition. Anim Behav. 54:737-746. DOI:10.1006/anbe.1997.0568

Soltis J et al. 2001. The interaction of male and female reproductive strategies and paternity in wild Japanese macaques, Macaca fuscata 62:485-494. DOI:10.1006/ anbe.2001.1774

Strum SC. 1982. Agonistic dominance in male baboons:an alternative view. International Journal of Primatology 3:175-202. DOI:10.1007/BF02693494

Strum SC. 1987. Almost Human: A Journey into the World of Baboons. New York:Random House.

Strum SC. 1994. Reconciling aggression and social manipulation as means of competition.1.life-history perspective. International Journal of Primatology 15:739-765. DOI:10.1007/BF02737429

Tutin CEG. 1979. Mating patterns and reproductive strategies in a community of wild chimpanzees (Pan troglodytes schweinfurthii). Behav Ecol Sociobiol 6:29-38. DOI:10.1007/BF00293242

Van Noordwijk MA. 1985. Sexual behavior of Sumatran long-tailed macaques (Macaca fascicularis). Ethology 70:277-296. DOI:10.1111/i.1439-0310.1985.tb00519.x

Van SchaikCP et al. 2004. A model for within-group coalitionary aggression among males. Behavioral Ecology 13:643652. DOI:10.1007/s00265-004-0818-1

Wroblewski E et al. 2009. Male dominance rank and reproductive success in chimpanzees, Pan troglodytes schweinfurthii. Animal Behavior 77:873-885. DOI:10.1016/j.anbehav.2008.12.014 